\title{
DE JAPANSCHE NIJVERHEID EEN GEVAAR?
}

Sedert jaren maken velen in Engeland en Amerika zich ernstig bezorgd over de ontwikkeling der Japansche industrie en voorspellen van die zijde gevaar voor de nijverheid van het Westen. Zij duchten den goedkoopen arbeid en den overvloed van arbeidskrachten in Japan, waar ,vier rijfden der bevolking" - — zoo heet het met groote overdrijving - in katoenspinnerijen en weverijen werkt ) en het hoogste loon yemiddeld niet meer dan 55 cents per dag bedraagt. Na de invoering der hoogere beschermende rechten zou de strijd voor het buitenland, zoo meende men, nog veel moeilijker worden.

Steeds meer blijkt dat deze bezorgdheid overdreven, of zelfs ongegrond moet worden genoemd. In een opmerkelijk artikel in het tijdschrift The Worlds Work kwam een Amerikaan, de heer Clarence Poe, eenigen tijd geleden tot de slotsom, dat de Japansche nijverheid nog in zeer vele jaren niet voor het Westen te duchten zal zijn en verklaarcle hij alle beweringen als zou de nijverheid der blanken voor die der Japanners moeten onderdoen, onomwonden voor praatjes. Wel geloofde hij dat de industrie in het Rijk der Opgaande Zon een toekomst heeft, maar niet dat haar ontwikkeling de Engelsche of Amerikaansche nijverheid bedreigt. Tot deze overtuiging was hij gekomen na de groote fabrieken zoowel als de kleine werkplaatsen in Tokio en Osaka gezien en met de eerzuchtige leiders der Japansche industrie gesproken te hebben.

$\mathrm{Er}_{\mathrm{r}}$ is volstrekt geen reden te gelooven, schreef Poe, dat Japan als nijverheidsstaat zich even sterk zou ontwikkelen als het als militaire staat is gegroeid. "Heel ons heden,"

1) In werkelijkheid slechts 486.508 in textielfabrieken, 191.561 in de zijdespinnerijen en 108.109 in de katoenspinnerijen. 
zoo zeide hem een Japanner, „,wortelt in ons verleden, en wij vergeten de hoofdzaak wanneer wij voorbijzien, dat Japan sinds vele eeuwen slechts voor soldaten bestaan heeft. De handelaar werd veracht, de industrie slechts als noodzakelijk kwaad geduld. Het Japan van de Jaloe, van Liaujang en Moekden is geen moderne Minerva, die in rolle wapenrusting uit het hoofd van Jupiter gesprongen is, het industrieele Japan is niets meer dan een leerling die den hoogen prijs der overwinning eerst nog met langen arbeid moet betalen."

Poe kwam in Japan, waar de arbeid zoo uiterst goedkoop is, tot precies dezelfde overtuiging; die hij ook in Amerika had opgedaan: dat weinig-kostende arbeid nooit goedkoop is. Dat had hem de negerarbeid in het Zuiden geleerd, wellicht de duurste op het Amerikaansche vasteland.

In Japan is het dagloon ongetwijfeld verbazend laag. Ziehier de statistiek van het Ministerie van Financiën voor het jaar 1910. Het dagloon bedroeg voor: timmerlieden 80 sen of 96 cts. (Nederl.), schoenmakers 63 sen of $79 \mathrm{cts}$, smeden 87 cts., zetters 63 cts., mannelijke boerenarbeiders 50 cts., mannelijke werers 55 cts., vrouwelijke arbeiders in weverijen 30 cts.

In de katoenweverijen van den eersten rang wisselen de loonen af tusschen $12 \frac{1}{2}$ cts. voor de kleinste kinderen en $621 / 2$ cts. voor flinke arbeidsters, in een mousseline-fabriek tusschen 25 cents en $f$ 1.25. En dat voor een dagelijkschen werktijd van elf uren en in een bedrijf dat groote inspanning en bedrevenheid eischt!

Ondanks deze roordeelen is de Japansche fabrieksarbeid' niet werkelijk goedkooper dan de Europeesche. „In de oude ambachten en huisnijverheid, waaraan ons volk gewend is," zeide een hoog Japansch ambtenaar, ,kunnen wij de wereld verslaan. Zoodra wij echter met de moderne machines en het grootbedrijf te doen krijgen staan wij voor honderd bezwaren. Ik heb dikwijls getracht een industrieel stelsel uit te werken, dat succes kan brengen en dat in Engeland, Duitschland of Amerika zeker succes zou hebben gebracht, maar dat hier in Japan in alle opzichten schipbreuk leed omdat er geen rekening gehouden was Econ. 1911. 
met de omstandigheden eener geheel andere omgeving, onze zoo geheel andere industrieele ontwikkeling. Als militairen mogen wij onovertroffen zijn - in de nijverheid moeten wij het ons getroosten, gedurende vele generaties geduldig te arbeiden tot wij de hoogte van het machinebedrijf in het Westen bereiken." De Amerikaansche schrijver verklaart, dat al zijn onderzoek en ervaring deze filosofie van zijn Japanschen zegsman bevestigd heeft. De directeur der Kanegafoetsji-spinnerij te Tokio, een maatschappij die 300.000 spindles heeft loopen, was slecht over den Japanschen arbeider te spreken. Een jong Engelschman van een andere fabriek zeide: ,Hier zijn vijf man noodig voor het werk dat ik thuis met een helper veriicht." Een Amerikaansche vice-consul meende: "Voor weefgetouwen zijn in Japan drie tot viermaal zooveel arbeiders noodig als in Europa." En een Japansch deskundige, die pas uit Europa teruggekeerd was: ,Lancashirewerk kost meer dan het onze maar het is ten slotte goedkooper.'

Het oordeel van den heer Poe stemt yrootendeels hiermede wereen. Maar hij acht den Japanschen arbeid slechts weinig goedkooper dan de Amerikaansche of Europeesche. Het verschil, zegt hij, is ten slotte niets anders dan een bloedhelasting op het leven en de geestkracht van het Japansche volk, als een gevolg van de omstandigheid, dat in Japan geen fabriekswet het moordende overwerk van vrouwen en kinderen verbiedt. Het stelsel werkt reeds hiercloor schadelijk, doordat het de vorming van krachtige arbeiders verhindert. Een onophoudelijke aanroer van de landhevolking verhoogt natuurlijk het peil van het werkvolk niet.

In het ambtelijke Japan Yearbook vindt men de meening uitgesproken, dat twee of drie bedreven Japansche arbejders met een vreemden werkman gelijk staan. Hierop heeft de schrijver in $T$ he $W$ or lds $W$ or $\mathrm{k}$ een bedenking van nog al gewicht: zijns inziens zijn er in Japan in 't geheel geen skilled 1 a bourers te vinden. Hij stond verhaasd toen een ambtenaar van het Ministerie van Landbouw en Handel hem mededeelde, dat de Japansche fabrieksarbeider gemiddeld minder dan twee jaren bij zijn werk blijft; die mededeeling wordt evenwel bevestigd. 
De Kanegafoetsji-maatschappij, die van alle Japansche fabrieken het best voor haar arbeiders zorgt, houdt haar arbeiders niet langer dan $2 \frac{1}{2}$ a 3 jaren. In een der eerste spinnerijen van Osaka, die 2500 arheiders in haar dienst heeft, zijn slechts $20 \%$ der arbeiders drie jaren lang werkzaam geweest. Onder zulke omstandigheden moet de ervaring der werklieden zeer gering zijn en het is geen wonder dat de regeering in haar Yearbook moet toegeven : ,,Een werkelijk nadeel van onze productie is het gebrek aan gelijkmatigheid in de kwaliteit, gevolg van onbedreven arbeid en te langen werktijd."

Erkend zij, dat alle takken van nijverheid in de laatste tien jaren sterk zijn uitgegroeid. Dat geldt voor katoenspinnerijen en textielfabrieken ran elken aard (sterk verminderde alleen de productie aan obiji, stoffen voor gordels), papier (Europeesch en Japansch), lucifers (een vermindering wel van het aantal fabrieken, maar bij ruim een verdubbeling van de productie), porselein- en aardewerk en de rest.

Maar de Japansche nijverheid is voor het grootste deel een vrouwelijke industrie. Op 307.139 mannen en knapen werkten er volgens de nieuwste opgaven (1909) niet min. der dan 493.498 vrouwen en meisjes en dezen zijn zevenmaal talrijker onder het fabriekspersoneel in Japan dan in Europa en Amerika. Meest komen deze arbeidsters van het land. Slechts twee of drie jaren willen zij in een fabriek werken, vóór zij trouwen. En duizenden van haar geven het werk op, róor den afloop van het contract of omdat haar ouders haar voor een huwelijk terugroepen of omdat zij lichamelijk reeds versleten zijn. Japan heeft bijna geen fabrieksarbeiders die het werk als hun beroep beschouwen.

Niet alleen in spinnerijen maar ook in vele andere bedrijven komt het buitengewoon primitieve van den Japan. schen arbeid aan den dag. Ik wilde, zegt de Amerikaansche schrijver, ,ik wilde, dat ik de in Kobe vervaardigde lucifersdoos, die op het oogenblik voor mij op tafel ligt, aan elken lezer van mijn artikel kon toonen. Nooit heb ik zulk een lucifersdoos in Amerika gezien. Bij ons zou ik in honderd doozen niet zooveel houtjes zonder kop, zooveel onbruikbare lucifers vinden als hier in één doos. En 
wat de fabricage betreft, is mij verteld, clat 5 of 6 Japansche lucifersarbeiders niet meer presteeren dan één bedreven vreemde arbeider." Huismoeders klagen algemeen: twee of drie Japansche dienstboden zijn noodig om het werk van een blanke dienstbode te doen. In een winkel verrichten twee of drie bedienden niet meer dan één bij ons. Een Japansch redacteur deelde mede, dat ook de Japansche zetters maar half zoo veel werk leveren als Amerikaansche. En een Amerikaansch kapitein zeide eens: "Ik was blij dat het koleninnemen in Nagasaki goed afliep. Wanneer het den dag, waarop mijn schip binnenkwam, geregend had, had ik zeker een dag moeten wachten voor het noodige aantal arbeiders bijeen was."

De Japansche fabrieksarbeiders werken langer dan die ran eenig ander land: elf uren per dag de eene week en cll uren per nacht in de andere. En dit niettegenstaande het volk in het algemeen buitengewoon afkeerig is van zwaren, onafgebroken arbeid. Een Japansch professor heeft gezegd: „Wij hebben een ader Maleisch bloed in ons en houden er van, nu en dan vrijal te nemen. Waarheid is, dat onze menschen geen arbeiders zijn, ze zijn kunstenaars en kunstenaars mogen niet worden aangespoord."

Het schijnt evenwel den Japanner niet mogelijk, zijn gewoonten van sierlijkheid en zorgvuldigheid mee te brengen in de nieuwe omgeving eener Europeesche fabriek. Reizigers verhalen dat bij de rijtuigen der electrische tram te Tokio de raderen zelden of nooit gereinigd of gesmeerd worden en dik in de roest staan. De spoortreinen zien er erbarmelijk uit, de telefoondienst is zoo mogelijk even slecht als de telegraafdienst. Een voormalig ambtenaar aan een Japansch departement vertelt, dat hij eens, na een telegram uit Osaka naar Kobe te hebben gezonden, zich met een riksja naar het station liet brengen, met den bommeltrein naar Kobe spoorde en - het huis dat hij bezoeken wilde, nog eerder bereikte dan zijn telegram.

De schuld van het slechte werk treft niet enkel de arbeiders, maar grootendeels ook de onervaren chefs. Het stelsel van den gezins- en huisarbeid dat sedert vele geslachten in Japan heerscht, is in de Japansche industrie blijven roortbestaan. Het zal daarom lang duren, alvorens 
voor de grootere bedrijven een genoegzaam aantal deskundige chefs gevormd is.

Dat de Japansche industrie niet wetkelijk zoo uitgebreid is, als men voorgeeft, blijkt uit de nieuwste ambtelijke sta tistiek volgens welke het aantal vrouwelijke fabrieksarbeiders in de laatste twaalf jaren gestegen is van 261.218 op 493.498, dat der mannelijke fabrieksarbeiders van 173.614 op 307.139. Een arbeidersbevolking van 800.637 hoofden in een land van 50.000.000 inwoners beteekent nog niet heel veel. Veel ,fabrieken" werken voorts met minder dan tien personen en zouden in Amerika niet tot de fabrieken gerekend worden.

Een groot nadeel voor de Japansche industrie is dat ijzer in het land ontbreekt; de eenige staalgieterij van den staat werkt voortdurend met groot verlies. De katoennijverheid, waar de loonen zeer laag zijn is in de laatste tien jaren niet merkbaar vooruitgegaan.

Dat leeren de cijfers van het Jaarboek met één oogopslag. Met uitzondering van zijden stoffen, waarvan de uitvoer natuurlijk verre den invoer overtreft, blijft in alle andere textielwaren de export sterk bij den import achter. Zoo voor $\mathrm{k}$ a toene $\mathrm{n}$ artikelen:

Uitvoer (1909) jen 51.880.074, (1910) jen 68.997.518.

Invoer " " 123.483.919, " " 174.474.600.

Voor andere textielstof $\mathrm{fen}$, met uitzondering van zijden :

Uitvoer (1909) jen 5.912.757, (1910) jen 6.618.569.

Invoer " "31.125.609, " "41.055.692.

Bij kleederen en toebehooren kan het uitvoer-surplus niet als een gunstig teeken voor de economische toestanden worden beschouwd. Evenmin als de vermeerderde invoet van Indische katoentjes voor een actieve nijverheid pleit. Een ongunstigen indruk maken ook de cijfers voor papier en papieren artikelen, waarin een Jand als Japan juist zou kunnen uitmunten. Integendeel vindt men roor den

Uitvo $r$ jen 4.961 .273 , jen 5.025.218, terwijl daarentegen werd Ingevoerd "8.714.114, ,8.848.098.

De uitroer van sigaretten nam af evenals die van onge- 


\section{8}

bleekte en gebleekte shirting, katoentijk, Europeesche klecderen, touw, zakken en stroomatten, chemische lucifers.

De behoefte aan machines blijkt dan ook sterk achteruit te gaan, althans in de beide laatste jaren. De invoer, die van bijna 15.000 .000 jen in 1904 plotseling steeg tot ruim 38.000 .000 jen in 1905 , daalde tot ruim 30 , rees tot bijna 47 millioen jen in 1908, doch viel in 1909 op ruim 28 millioen en in 1910 op ruim 23.000 .000 jen. De invoer van spinnerij-machines verminderde van 4.100 .000 in 1909 op 2.600 .000 in $1910 .{ }^{1}$ )

Bij de grondstoffen nam de invoer van ruwe katoen af, die ran gezuiverde toe; de invoer van blokijzer nam af, clie ran staal in blokken en staven toe.

De Japansche handelsvloot heeft zich niet in die mate untwikkeld als men wellicht van de hooge haar toegelegde subsidiën heeft verwacht. Wel vermeerderde het laadvermogen van rond 1.000 .000 ton in 1906 tot bijna 1.025.000 ton in 1910 bij de stoomschepen en $\tan 354.000$ op $413.0(1)$ ton bij de zeilvloot, maar de jaarlijksche toeneming vertoont niet meer de sterke uitbreidingsbehoefte van vroeger. Een stijging van bijna 80.000 ton van 1906 op 1907 werd rervangen door een stijging van jaarlijks niet meer dan 35.000 tot 44.000 ton in de daarop volgende vier jaren. De stoomschepen zijn roor 't meerendeel klein en evenals de zeilschepen slechts bruikbaar roor de kleine vaart. Stoomboten van meer dan 10.000 tons zijn in de Japanwhe handelsmarine nog steeds een groote zeldzaamheid. Alleen moet etkend worden, dat de Japansche scheepsbouw zich langzamerhand van het buitenland onafhankelijk maakt. Op de scheepswerven hebben de groote staatssubsidiën doel getroffen.

Hierbij moet in het oog gehouden worden, dat de loonen in Japan vourtdurend stijgen en verder stijgen zullen. Uit een staatje van de loonen in 46 bedrijven over een tijd van acht jaren, roorkomende in het $F$ in a $n c$ i a 1 a n cl Economic Journal, ziet men dat het loon in geen enkele groep gedaald, en slechts in twee groepen minder dan $30 \%$ gestegen, in zestien met 30 tot 40 , in

1) Ronde getallen. 
zeventien met 40 tot 50 , in acht met 50 tot 60 , in drie met 60 tot $70 \%$ vermeerderd is. De grootste verhooging onderging het loon voor vrouwelijke dienstboden, grootendeels een gevolg van de concurrentie der labrielien. Volgens opgaven van den Engelschen vice-consul is te Osaka het dagloon voor mannen in de laatste drie jaren met 30 $\%$, van vrouwen en meisjes met $25 \%$ vermeerderd. De omvang van vrouwenarbeid in fabrieken wordt voorts beperkt cloor de vroege huwelijken.

En bij dit alles komt de stijging der kosten van het levensonderhoud in Japan ran jaar tot jaar, ten deele tengevolge van de hoogere behoeften, die de moderne beschaving teweegbrengt, roor het grootste deel door den untzettenden belastingdruk waaronder het rolk zucht. De Japanner heeft, naar men algemeen aanneent, ongeveer 30 tot $35 \%$ van zijn inkomen aan belastingen te betalen, maar hierbij is buiten rekening gelaten de zware last, dien de monopolisatie voor zout en tabak het volk oplegt. En sinds in Juli het nieuwe hooge beschermende tarief in werking is getreden, zal de toestand er niet beter op worden.

In acht jaren zijn de directe belastingen met $119 \%$ vermeerderd; de nationale schuld steeg van 10.70 jen per hoofd in 1900-1 tot 50.02 jen per hoofd in 1909-10. ${ }^{1}$ ) Wat Japan vooral noodig heeft is een korps oude, ervaren arbeiders, die den jongeren iets leeren kumnen. In de groot-industrie ontbreekt zull; een korps geheel. Maar een $n o g$ bedenkelijker gemis is het ontbreken van den ondergrond van zulk een veelzijdig ontwikkeld, degelijk handwerk als waaruit de industrie van het Westen geleidelijk is opgegroeid. Het uiterst primitiere oud-Japansche kunstambacht is daarvoor rolkomen ongeschikt. Het is geestelijk van te fijne beschaving, stoffelijk echter ondegelijk en onstevig.

Vervolgens is er geen ondernemingsgeest in Japan, of, waar zich initiatief vertoont, treedt aanstonds de alles absorbeerende staat op $\mathrm{cm}$, in cle vorm van monopoliën op tahak, kamfer, zout, - de vruchten van den ondernemings-

1) 1 jen is pl. m. f 1.20 . 
geest zich toe te eigenen en het iedereen af te leeren, zijn eerzucht te ontplooien. De regeering begunstigt alleen eenige halfambtelijke grootkapitalisten, grootindustrieelen en kooplieden die tot taak hebben den rechtstreekschen handel op het buitenland voor Japan in beslag te nemen en den vreemden handelaar overal uit te drijven. Ten slotte, wanneer alle concurrentie onmogelijk is geworden, zal natuurlijk het volk het gelag moeten betalen.

Zoo moet ieder onbevooroordeeld toeschouwer dan erkennen, dat de Japansche nijverheid nog in vele jaren niet in staat zal zijn, ernstig met die van het Westen te dingen. Japans oud handwerk is in alle opzichten onvoldoende en gebrekkig, een herleving van het eenmaal beroemde kunstambacht, dat onder de begunstiging der Samoerai - d.w.z. in een atmosfeer van behagelijkheid en tijdruimte - kon leven is onmogelijk nu de eischen zijn: vlug werk, snel leveren, veel verdienen in korten tijd. Maar de arbeider van den nieuwen tijd is zwak, slecht gevoed, veranderlijk en niet in staat een constant degelijk product te leveren. Het succes der moderne industrie was tot dusver meestal een schijnsucces en waar uitvoer slaagde, gelukte dit dank aan hooge staatssubsidiën of op kosten van de aandeelhouclers, die telkens opnieuw hun kapitaal verloren.

Aan verovering der wereldmarkt valt voor Japan binnen afzienbaren tijd nog niet te denken:

H. S. M. van Wickevoort Crommelin. 